\title{
Bioconstrução Coletiva na Aldeia Itapoã Tupinambá de Olivença, Ilhéus, BA, Brasil
}

\author{
Leandro Ricardo dos Santos Souza ${ }^{1}$, Vanessa Rodrigues dos Santos ${ }^{1} \&$ Silvia Kimo Costa ${ }^{1}$
}

Recebido em 02/09/2020 - Aceito em 16/02/2021

1 Universidade Federal do Sul da Bahia/UFSB. Rodovia de Acesso para Itabuna, km 39 - Ferradas, Itabuna/BA, Brasil. CEP: 45.613-204. <leolano@gmail.com, bisarte@hotmail.com,skcosta@ufsb.edu.br>.

\begin{abstract}
RESUMO - O presente texto aborda, por meio do relato de experiência, o processo de aprimoramento da tecnologia bioconstrutiva vernacular de edificações na aldeia indígena Itapoã Tupinambá, localizada no distrito de Olivença, município de Ilhéus/BA, Brasil. As atividades pautaram-se na abordagem teórico-metodológica da pesquisa-ação, uma vez que a construção vernacular não pode ser dissociada do coletivo representativo da realidade investigada. As atividades contemplaram: a) registro em diário de campo; b) análise de patologias de edificações através de um roteiro de observação direcionada; $e$ c) oficinas de bioconstrução. Observou-se que as edificações da aldeia são predominantemente construídas com terra, utilizando a tecnologia bioconstrutiva do pau-apique. Constataram-se patologias referentes à deterioração, irregularidades e fissuras provocadas pela retração do barro. A partir de vivências de bioconstrução, foi possível aprimorar a argamassa natural utilizada, contribuindo para melhoria do desempenho estrutural das edificações em curto $e$ médio prazos. Concluiu-se que a manutenção da bioconstrução em pau-a-pique retarda o impacto ambiental resultante do uso de materiais convencionais, além de assegurar aspectos socioculturais intrínsecos ao processo de construção em mutirão na comunidade.
\end{abstract}

Palavras-chave: Comunidades tradicionais; bioarquitetura; edificação bioconstruída.

\section{Collective Bioconstruction in the Itapoã Tupinambá Indigenous Village of Olivença, Ilhéus, BA, Brazil}

\begin{abstract}
This text addresses, through the experience report, the process of improvement of vernacular bioconstructive technology of buildings in the Indigenous Village Itapoã Tupinambá, located in the district of Olivença, municipality of Ilhéus/BA, Brazil. The activities were guided by the theoretical-methodological approach of research-action, since the vernacular construction cannot be dissociated from the collective representative of the reality to be investigated. The activities included: a) recording in a field diary; b) analysis of building pathologies through an observation script and; c) bioconstruction workshops. It was observed that the buildings of the village are predominantly built with earth, using the bioconstructive technology of wattle and daub. Pathologies related to deterioration, irregularities and cracks caused by the retraction of the clay were found. From Bioconstruction experiences it was possible to improve the natural mortar used, contributing to improve the structural performance of buildings in the short and medium terms. It was concluded that the maintenance of bioconstruction in wattle and daub delays the environmental impact resulting from the use of conventional materials, in addition to ensuring socio-cultural aspects intrinsic to the collective construction process in the community.
\end{abstract}

Keywords: Traditional communities; bioarchitecture; bioconstructed building.

\section{Bioconstrucción Colectiva en la Aldea de Itapoã Tupinambá de Olivença, Ilhéus, BA, Brasil}

RESUMEN - Este texto aborda, a través del relato de experiencia, el proceso de mejoramiento de la tecnología bioconstructiva vernacular de edificaciones en la Aldea Indígena Itapoã Tupinambá, ubicada en el distrito de Olivença, municipio de Ilhéus/BA, Brasil. Las actividades se guiaron por el enfoque teórico-metodológico de investigación- acción, ya que la construcción vernácula no puede disociarse del colectivo representativo de la realidad a investigar. Las actividades incluyeron: a) registro en un diario de campo; b) análisis de patologías de la edificación a través de una guión 
de observación direcionada; y c) talleres de bioconstrucción. Se observó que las edificaciones del pueblo están predominantemente construidas con tierra, utilizando la tecnología bioconstructiva de bareque o bahareque. Se encontraron patologías relacionadas con el deterioro, irregularidades y fisuras provocadas por la retracción de la arcilla. A partir de las experiencias de Bioconstrucción se logró mejorar el mortero natural utilizado, contribuyendo a mejorar el desempeño estructural de las edificaciones en el corto y mediano plazo. Se concluyó que el mantenimiento de la bioconstrucción en bareque o bahareque que retrasa el impacto ambiental derivado del uso de materiales convencionales, además de asegurar aspectos socioculturales intrínsecos al proceso de construcción colectiva en la comunidade.

Palabras clave: Comunidades tradicionales; bioarquitectura; edificio bioconstruido.

\section{Introdução}

A arquitetura vernacular é uma tipologia influenciada por condições geográficas, climáticas e por aspectos socioculturais, cujo processo construtivo geralmente ocorre de maneira coletiva e é transmitido através das gerações (Hărmănescu \& Enache, 2016; Donovan \& Gkartzios, 2014; Oliver, 2006; Asquith \& Vellinga, 2005). Já a bioconstrução pode ser entendida como uma cultura construtiva que utiliza conceitos, práticas $e$ aperfeiçoa técnicas para o uso de materiais, advindos da arquitetura vernacular (Catarino, 2006).

Para Coimbra (2017), tanto a arquitetura vernacular quanto a bioconstrução podem ser consideradas "construções naturais", pois "emprega o mínimo possível de processos e materiais industrializados e se caracteriza, formal e tecnicamente, pela presença de materiais naturais e técnicas construtivas de pouca complexidade tecnológica".

Segundo Santos \& Costa (2018), no Brasil as principais tipologias vernaculares são: o adobe, o pau-a-pique, as palafitas, o flutuante, o sistema tábuas-mata-junta e o enxamiel. As tipologias variam de acordo com as condições geográficas e climáticas das regiões do Brasil. Especificamente no que se refere ao pau-a-pique, Pinheiro (2010) relata que a maior concentração de edificações está situada no nordeste brasileiro.

$\mathrm{O}$ autor destaca que em comunidades tradicionais (remanescentes das comunidades de quilombos e aldeias indígenas) tal técnica construtiva é uma referência de construção sustentável do ponto de vista sócio-econômicoambiental-cultural, pois, "a partir de uma integração com os recursos locais disponíveis, contribui para a revisão de conceitos e princípios dos atuais paradigmas socioculturais da sociedade moderna com seu sistema construtivo natural" (Pinheiro, 2010).
Considerando o exposto, este artigo apresenta, por meio do relato de experiência, o processo de aprimoramento da tecnologia bioconstrutiva vernacular de edificações na aldeia Itapoã, localizada na terra indígena dos Tupinambá, em Ilhéus, Bahia. As atividades contribuíram para assegurar os aspectos socioculturais intrínsecos a tal processo, que ocorre de maneira coletiva, e minimizar ou retardar os impactos ambientais advindos da construção convencional.

\section{Metodologia}

\section{Abordagem teórico-metodológica da pesquisa-ação}

Tanto a arquitetura vernacular quanto a bioconstrução possibilitam a redução do consumo energético durante o processo construtivo, pois utilizam estratégias de conforto e proteção a um baixo impacto ambiental no sistema local (Garrido et al., 2016; Pinha et al., 2015; Obata \& Ghattas, 2012).

Pontua-se que é comum encontrar o termo bioconstrução associado à permacultura e à agroecologia (Ribeiro, et al., 2018; Monteiro \& Pires, 2017; Camillis, 2016). Entende-se que essa associação ocorre porque os três termos envolvem o pensamento sistêmico de integração Ser Humano - Natureza, objetivando a minimização dos impactos socioambientais causados pela ocupação antrópica (Santos et al., 2019).

Para compreender a bioconstrução segundo o pensamento sistêmico, a pesquisa não se restringiu à descrição das tecnologias construtivas empregadas e/ou análise de materiais, mas considerou, principalmente, os aspectos etnobiológicos intrínsecos ao processo bioconstrutivo (Amaro, 2017). E, para a descrição e análise de tais aspectos, utilizou-se uma abordagem teórico-metodológica em que 
os/as pesquisadores/as deixaram de exercer "a suspensão de julgamento" e se tornaram atores participantes-ativos do processo (Damascedo, 2018; Siolari et al., 2010).

Sendo assim, a pesquisa pautou-se na abordagem teórico-metodológica da pesquisaação que pode ser entendida como uma pesquisa social que envolve a participação de um coletivo de pessoas para solução de um problema, sendo que esse coletivo é representativo da realidade a ser investigada (Thiollent, 1985). Trata-se de uma metodologia de pesquisa cooperativa $e$ participativa.

De acordo com Baldisserra (2001):

Uma pesquisa pode ser qualificada de pesquisaação quando houver realmente uma ação por parte das pessoas implicadas no processo investigativo, visto partir de um projeto de ação social ou da solução de problemas coletivos e estar centrada no agir participativo e na ideologia de ação coletiva.

Segundo Tripp (2005) a pesquisa-ação deve ser reconhecida:

(...) como um dos inúmeros tipos de investigaçãoação, que é um termo genérico para qualquer processo que siga um ciclo no qual se aprimora a prática pela oscilação sistemática entre agir no campo da prática e investigar a respeito dela. Planeja-se, implementa-se, descreve-se e avalia-se uma mudança para a melhora de sua prática, aprendendo mais, no correr do processo, tanto a respeito da prática quanto da própria investigação.

Dessa forma, considerou-se que não só as/ os pesquisadoras/es, mas a comunidade da aldeia Itapoã Tupinambá de Olivença, que vivencia a solução problema, fazem parte do processo de coleta, análise e reflexão quanto aos resultados.

\section{A aldeia indígena Itapoã Tupinambá de Olivença}

A aldeia indígena Itapoã localiza-se no distrito de Águas de Olivença, município de Ilhéus, Bahia e pertence à terra indígena Tupinambá, identificada e delimitada pela Funai. A demarcação da Terra está em processo de reconhecimento. A área em branco da Figura 1, corresponde à terra indígena Tupinambá e o círculo laranja à aldeia Itapoã.



Figura 1 - Mapa temático da terra indígena Tupinambá, Ilhéus, BA. Fonte: Elaborado pelos autores com base no Relatório Antropológico, FUNAI, Ilhéus, BA (2018). 
De acordo com Santos \& França (2009), a região apresenta clima litoral úmido, caracterizada por microclima quente, úmido e sub-úmido, com temperaturas anuais variando entre $20^{\circ}$ e $30^{\circ} \mathrm{C}$. As chuvas são regulares ao longo do ano e mais abundantes nos meses de maio a agosto. As taxas anuais de precipitação podem chegar até $2.400 \mathrm{~mm}$.

Segundo Costa (2019) a ocupação da área da aldeia Itapoã ocorreu em 2007 em uma pequena clareira do remanescente da Mata Atlântica.

(...) próxima do mar e da Rodovia que liga o município de Ilhéus ao município de Una. Habitações subsequentes foram construídas lado a lado no sentido do sul para o norte, formando uma via de acesso principal central. As habitações estão dispostas para aproveitar a incidência solar matinal e a brisa do mar. Fachadas de frente para o oeste são sombreadas pela Mata local (Costa, 2019, p. 72).

Atualmente vivem cerca de 50 famílias na aldeia.

Os materiais para construção das habitações em pau-a-pique são obtidos in loco. Da mata local (remanescente da Mata Atlântica) são extraídos os espécimes usados para a estrutura, sendo estes: Biriba - Eschweilera ovata Cambess. Mart. Ex Miers; Aderno - Emmotum affine Miers; Inhaíba - Lecythis lurida (Miers) S. A. Mori e Musserengue - Vochisia lucida Klotzsch ex M.R. Schomb (Costa, 2019).

Já o revestimento é constituído por argamassa de barro. De maneira geral, o solo da aldeia Itapoã é classificado como Argissolo (Santos et al., 2006), com predominância de grãos microscópicos, cor viva (avermelhado $e$ amarelado) e alta impermeabilidade (Santos \& Costa, 2020).

\section{Etapas da pesquisa-ação}

Etapa 1 - Imersão das/os pesquisadoras/es na aldeia Itapoã Tupinambá de Olivença para acompanhar o processo bioconstrutivo vernacular das edificações. Essa etapa ocorreu de agosto a novembro de 2019 e consistiu em visitas semanais da equipe à aldeia.
Etapa 2 - Diagnóstico quanto à patologia das edificações. Tal etapa ocorreu nos dias 07 e 08 de setembro de 2019. Foi elaborado um roteiro de observação direcionado com base em Moroni Filho (2017) e Olender (2006). Três aspectos foram analisados:

a) existência de deterioração, irregularidades e danos estruturais;

b) existência de fissuras e esmagamento e;

c) Irregularidades geométricas.

Etapa 3 - Vivências de Bioconstrução. A primeira nos dias 11 e 12 de outubro de 2019, objetivou aprimorar a argamassa de barro que reveste a estrutura do pau-a-pique, como objeto de intervenção foi escolhida as salas de aula para a educação de jovens e adultos (EJA). A segunda nos dias 09 e 10 de novembro de 2019, objetivou aplicar a pigmentação feita a partir de "terra" colorida. Pontua-se que as datas foram definidas em conjunto com a Comunidade sob recomendação da liderança da aldeia e compreenderam os sábados e domingos, dias em que as pessoas que aceitaram participar das vivências estavam disponíveis em tempo integral.

Participaram entre 20 e 30 pessoas nas duas vivências, incluindo adultos (homens e mulheres), adolescentes e crianças.

A vivência dos dias 11 e 12 de outubro de 2019 contemplou as seguintes atividades: 1) extração do solo argiloso avermelhado e do solo argiloso amarelado, ambos disponíveis em grande quantidade na aldeia; extração da palma (também abundante na aldeia) e da piaçava; 2) teste de proporção e mistura do material, por meio do processo de pisoteio. Os resultados apresentam a descrição das proporções utilizadas.

A vivência dos dias 09 e 10 de novembro de 2019, contemplou as seguintes atividades: 1) identificação e orientação para extração do solo colorido disponível na aldeia; 2) orientação para separação por cor e da proporção da água e "baba" de palma a ser acrescentada para conformação do pigmento; 3) orientação para aplicação do pigmento nas paredes da EJA.

Todas as etapas seguiram o Protocolo de aprovação do Conselho Nacional de Ética em Pesquisa (CONEP) n 2.552.460/ 2018 do projeto, ao qual a pesquisa está vinculada. 


\section{Resultados e discussão}

\section{Descrição do processo bioconstrutivo vernacular das edificações na aldeia Itapoã}

O pau-a-pique é uma tipologia de construção com terra composta por estrutura de ripas de madeira ou bambu, preenchidas com barro e fibra (Barbosa et al., 2011). Segundo Santos \& Costa (2018), pode ser considerado uma referência de construção sustentável do ponto de vista sócio-econômico-ambiental-cultural, pois apresenta baixo consumo de energia associado.

Na aldeia Itapuã, a construção em pau-apique é realizada conforme as seguintes etapas:

1 - Escolha do local onde será construída a edificação.

2 - Mutirão (toda a comunidade) para coleta dos materiais que estruturam a edificação.

3 - Montagem da estrutura da edificação e da trama (composta por galhos amarrados com cipó ou fixados com pregos) que sustentarão a argamassa de barro. Essa etapa é realizada por três ou quatro pessoas. A trama é composta por esteios verticais de 5 a $8 \mathrm{~cm}$, e caras horizontais de 2,5 a $4 \mathrm{~cm}$.

4 - Cobertura da estrutura com telhas de fibrocimento (constituídas por fibras de amianto e cimento). Também realizada por três ou quatro pessoas. As telhas são adquiridas em lojas de materiais de construção no município de Ilhéus, independente de fabricação local ou externa.

5 - Mutirão (Toda a Comunidade) para taipagem. Essa etapa compreende a coleta do solo in loco; o preparo da argamassa; o "pisoteio" (mistura); o transporte da argamassa (em baldes e/ou carrinhos de mão) e o "barrear". O barrear é o processo de cobertura da trama com a argamassa de argila que foi preparada. A argamassa é lançada com as mãos nos dois lados da trama e pressionada. A espessura da parede varia de 10 a $20 \mathrm{~cm}$.

As etapas ocorrem em épocas diferentes, pois dependem da pluviosidade. A taipagem é inviabilizada em dias de chuva, por esse motivo a construção de uma edificação leva cerca de 45 a 60 dias para ser concluída.

\section{Diagnóstico quanto às patologias das edificações em pau-a-pique}

Antes da realização das vivências de bioconstrução, para aprimorar o processo construtivo em pau-a-pique, procedeu-se com o diagnóstico da estrutura das edificações. Segundo Olender (2006) as patologias em pau-a-pique podem ser divididas em três grupos: física, mecânica ou química.

Física: as lesões que compõem esse grupo geralmente se manifestam devido à presença de água no edifício ou no seu entorno. Incluem-se também neste grupo as manchas provocadas por sujidades e o tipo de erosão provocado pela ação dos agentes atmosféricos. (...) Mecânica: as lesões que compõem esse grupo caracterizamse tanto pelo aparecimento de fissuras, pela alteração de forma e pelo desgaste das superfícies dos elementos atingidos, quanto pela perda de trechos principalmente de revestimentos. (...) Química: as lesões desse grupo estão relacionadas a processos patológicos de caráter químico, cujas causas estão normalmente associadas à presença de sais, de organismos vivos ou de produtos ácidos (Olender, 2006, p. 74-80, grifo nosso).

O diagnóstico realizado durante os dias 07 e 08 de setembro de 2019, indicou a existência de patologias físicas e mecânicas (Quadro 1). Relatase que o traço da argamassa de barro (utilizada para o preenchimento da trama de madeira do pau-a-pique) varia de acordo com o solo disponível no local.

O solo geralmente é composto por areia, silte, argila, e misturas arenosas (grande quantidade de areia) e argilosas (grande quantidade de argila). O solo arenoso, tende a ter pouca liga ou pouca coesão entre os grãos e "esfarela" quando submetido à abrasão, já o solo argiloso tende a ter muita liga ou coesão, por esse motivo apresenta tensão interna que provoca a retração $e$ fissuras à medida que perde água (Neves \& Farias, 2011).

Cabe pontuar o que se entende por "barro", "terra" e "solo". Os termos "barro" e "terra" são comumente empregados em construções vernaculares ou bioconstruções (Pisani, 2004). Já por "solo" compreende-se:

Uma coleção de corpos naturais, constituídos por partes sólidas, líquidas e gasosas, tridimensionais, dinâmicos, formados por materiais minerais 
e orgânicos que ocupam a maior parte do manto superficial das extensões continentais do nosso planeta, contém matéria viva e podem ser vegetados na natureza onde ocorrem $e$, eventualmente, terem sido modificados por interferências antrópicas (Santos et al., 2006, p. 31).

Constatou-se que as paredes das edificações apresentavam fissuras variando de $1 \mathrm{a} 20 \mathrm{~mm}$. Isso ocorreu porque a argamassa de barro utilizada foi composta, predominantemente, por solo argiloso avermelhado. Verificou-se também que a madeira usada para estruturar o pau-a-pique foi fixada diretamente no solo e sem prumo, aumentando a deformidade das paredes. Os esteios foram fixados a cerca de 40 a $80 \mathrm{~cm}$ de profundidade, por meio do apiloamento. $\mathrm{O}$ diâmetro das peças variou de 14 a $18 \mathrm{~cm}$ e o comprimento de 3 a $5 \mathrm{~m}$.

O desaprumo ocorreu porque os esteios (peças dispostas verticalmente) foram alinhados apenas com o olhar, apiloados e reajustados ao mesmo tempo, e a madeira coletada na mata local apresenta, em sua maioria, nós e arcos.

Quadro 1 - Avaliação do pau-a-pique das edificações da aldeia indígena Itapoã.

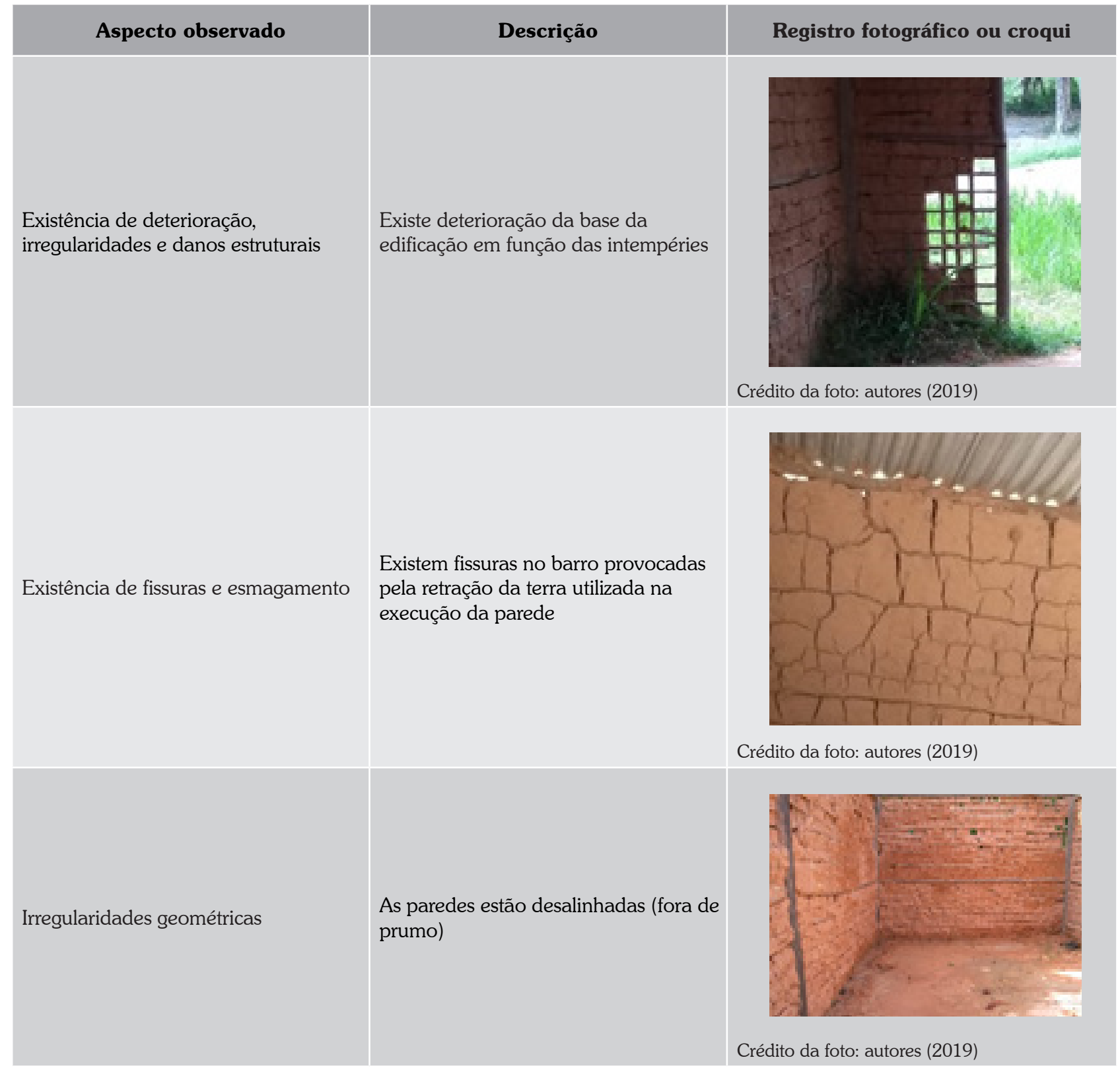

Elaborado pelos autores. 


\section{Vivências de bioconstrução}

Considerando o diagnóstico, durante as vivências dos dias 11 e 12 de outubro de 2019, foram realizadas oficinas para corrigir as fissuras, a deformidade e melhorar a resistência das paredes. Como objeto de intervenção foi escolhida as salas de aula para a EJA, construída em pau-a-pique em agosto de 2019 pela comunidade (Figura 2).

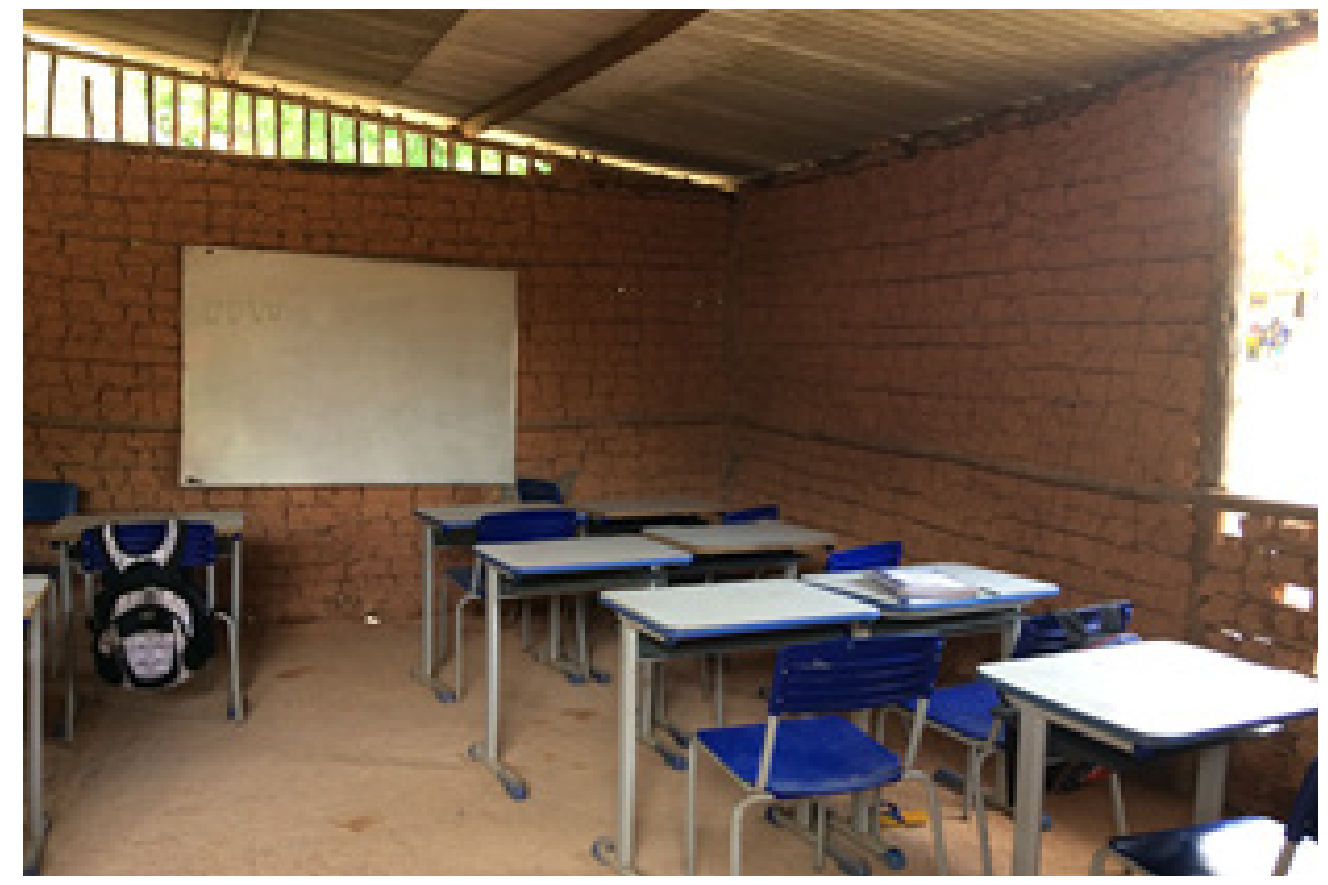

Figura 2: Salas de aula para EJA na aldeia Itapoã. Fonte: Acervo pessoal dos autores.

Sugeriu-se o revestimento com argamassa de barro melhorada. Para reduzir a coesão e obter um baixo índice de retração foi proposta a mistura do solo argiloso avermelhado com solo argiloso amarelado (que apresenta menor teor de argila), ambos disponíveis em grande quantidade na aldeia.

Três testes de proporção foram realizados. No primeiro, misturou-se quantidades iguais (um balde) de solo argiloso avermelhado e de solo argiloso amarelado. A água foi adicionada aos poucos. Observou-se a redução da liga, mas a argamassa ainda apresentou fissuras depois da secagem, da ordem de 1 a $3 \mathrm{~mm}$.

No segundo teste, misturou-se um balde de solo argiloso avermelhado, dois baldes de solo argiloso amarelado e água (adicionada aos poucos). Esse traço não apresentou fissuras ou microfissuras, contudo teve baixa resistência à abrasão.

No terceiro teste, outros materiais, também disponíveis em abundância na aldeia, foram adicionados: fibras de piaçava (um balde) $e$ "baba" de palma (um balde). De acordo com Neideck, Granato \& Funfgelt (2020), a fibra da piaçava faz com que a argamassa suporte as tensões de retração durante a secagem e evita as rachaduras. Já a "baba" de palma, assim como o esterco, possibilita maior aderência da argamassa, resistência à abrasão e melhoria da impermeabilidade (Brito, 2019). Sendo assim, após o terceiro teste, obteve-se uma argamassa com redução da liga, resistência à abrasão, de maior maleabilidade e rendimento.

Por fim, a argamassa foi composta por: solo argiloso avermelhado, solo argiloso amarelado, água, fibra de piaçava e "baba" de palma. O traço foi definido para uma área de cobertura inicial de $4 \mathrm{~m}^{2}$. Foram utilizados um carrinho de mão (caçamba de fundo plano com capacidade de 50 litros) de solo argiloso avermelhado e três de solo argiloso amarelado (o equivalente a 8 baldes de 12 litros); dois baldes de fibra de piaçava e dois baldes de "baba" de palma. Traço em baldes: 8: 2: 2. A água foi acrescentada aos poucos enquanto ocorria o processo de mistura por meio do pisoteio. 
A Figura 3 ( $\mathrm{a}, \mathrm{b}$ e c) mostra o processo de maceração da palma extraída na aldeia, o descanso em água e o preparo da piaçava. A Figura 4 ( $\mathrm{a}$ e b) apresenta a mistura do solo argiloso avermelhado ao solo argiloso amarelado e aplicação da argamassa de barro melhorada nas paredes das salas de aula EJA.

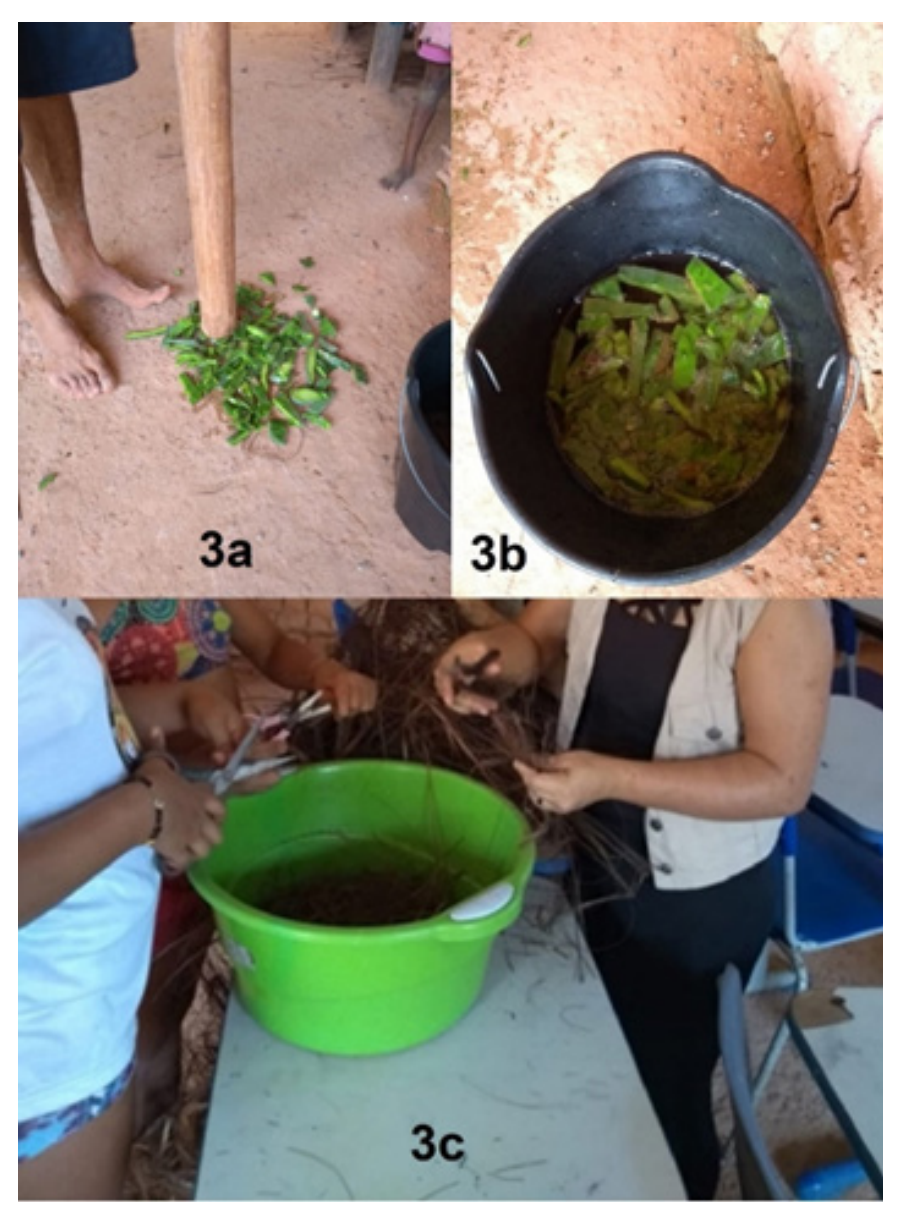

Figura 3 - Maceração da palma, descanso em água e preparo da piaçava. Fonte: Acervo pessoal dos autores.

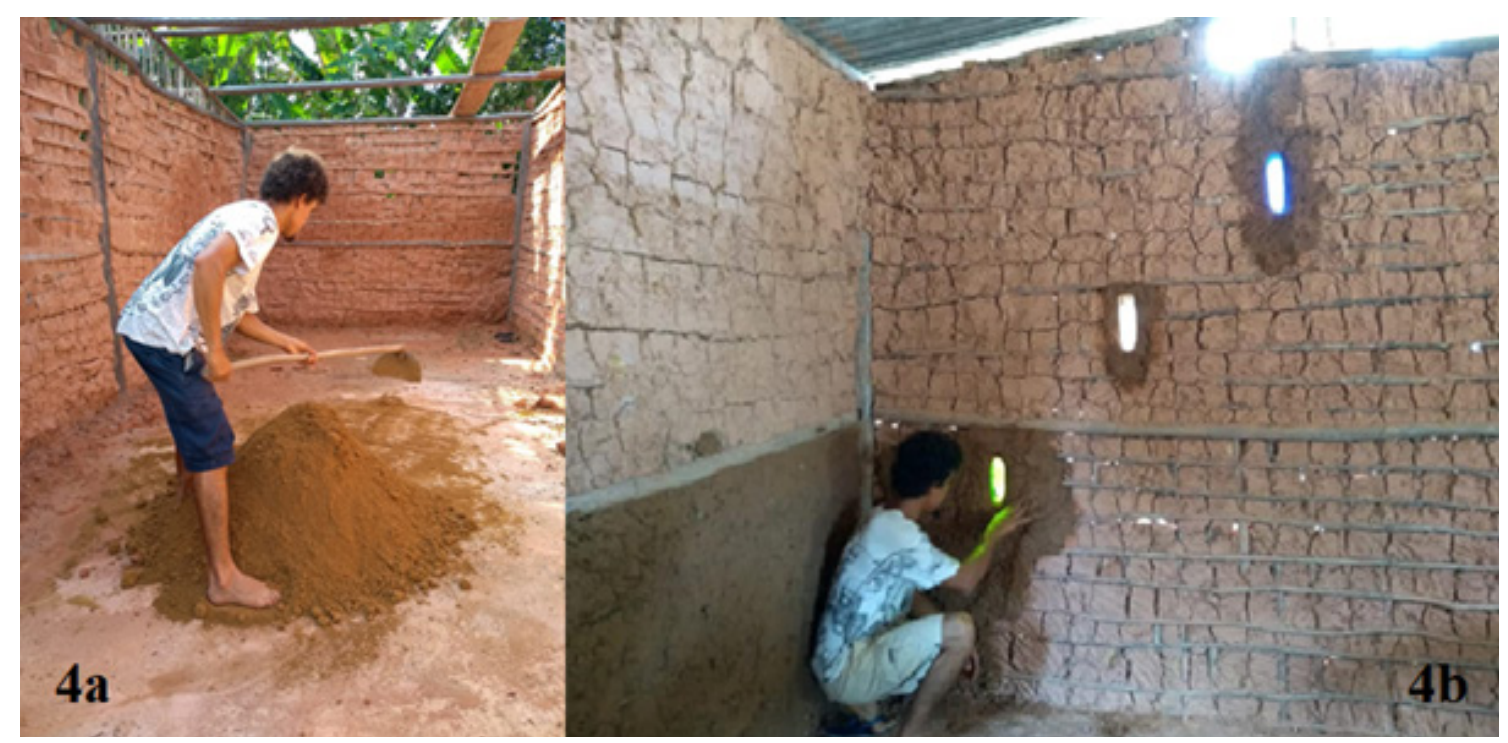

Figura 4 - Mistura do solo argiloso avermelhado com o solo argiloso amarelado e aplicação da argamassa de barro melhorada nas paredes das salas de aula EJA. Fonte: Acervo pessoal dos autores. 
As vivências dos dias 09 e 10 de novembro de 2019 objetivaram finalizar o processo de revestimento das paredes e aplicar a pigmentação feita a partir de "terra" colorida. A Figura 5 ( $\mathrm{a}$ e b) mostra a extração da terra, separação por cor e a aplicação dos pigmentos em uma das paredes da sala de aula.

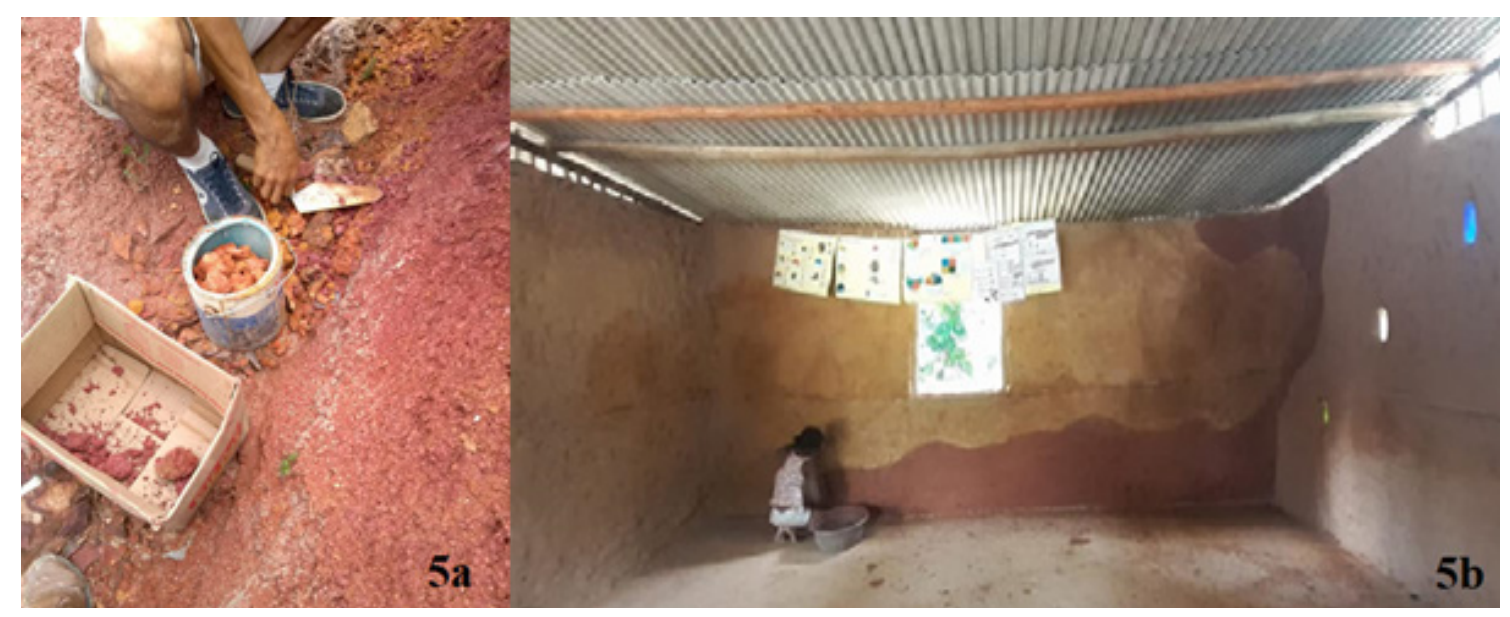

Figura 5 - Extração da terra e separação por cor e a aplicação dos pigmentos em uma das paredes da sala de aula EJA. Fonte: Acervo pessoal dos autores.

Decorridos 30 dias após as vivências, realizou-se um novo diagnóstico. Constatou-se que a deformidade das paredes foi consideravelmente reduzida; não houve reincidência de fissuras e a base da edificação apresentou maior resistência à chuva, embora seja imprescindivel aumentar a extensão do beiral de $30 \mathrm{~cm}$ para $1 \mathrm{~m}$.

Pontua-se que, embora as paredes de paua-pique permitam a moderação do microclima dos ambientes, a cobertura em fibrocimento faz com que as edificações fiquem quentes $e$ desconfortáveis. Conforme verificado por Costa (2019), a aldeia não dispõe de recursos financeiros para aquisição de telhas cerâmicas e não é possivel extrair o maribu em quantidade suficiente para cobrir todas as edificações sem impactar o ecossistema local.

Uma alternativa seria a taubilha de madeira (cavaca) ou o bambu, pois além de apresentar pegada de $\mathrm{CO}_{2}$ (na produção primária) menor em relação à telha cerâmica, tais coberturas viabilizam isolamento térmico e manutenção do conforto higrotérmico de edificações em localidades de clima quente e/ou frio (Alves, 2018).

\section{Considerações finais}

A manutenção da construção com terra que, na aldeia Itapoã, ocorre por meio do pau-a-pique possibilita não só a preservação do ecossistema local, mas impede (ou retarda) o impacto ambiental resultante do uso de materiais e tecnologias construtivas convencionais. Segundo Monte (2014) a construção com terra apresenta baixo custo, pois a matéria prima é extraída in loco e envolve o processo de autoconstrução; tem baixo impacto energético de produção e consequentemente minimiza o impacto ao meio ambiente. Sharma et al. (2016) e Macedo (2010), argumentam que a redução do impacto ambiental ocorre sob diversos aspectos. Dentre os quais destacam-se: 1) emissões de $\mathrm{CO}_{2}$ praticamente nulas, pois não envolve queima durante o processo de produção primária e nem ao fim do ciclo de vida; e 2) a terra é biodegradável e pode ser reutilizada.

Reitera-se que as edificações da aldeia Itapoã, em sua maioria, apresentam patologias físicas e mecânicas resultantes do processo construtivo. Sendo assim, as vivências de bioconstrução voltaram-se para a capacitação da comunidade quanto ao aprimoramento de tal processo. Tomou-se como objeto de intervenção as salas de aula onde ocorrem as atividades da EJA. Após as vivências verificou-se que as paredes das salas de aula apresentaram maior resistência e durabilidade.

Pontua-se, ainda, que o microclima interno das habitações pode ser melhorado se a cobertura 
em fibrocimento for substituída por taubilhas (cavacas) de madeira ou bambu produzidos in loco. Especificamente em relação ao bambu, a técnica construtiva é simples, pois as peças são confeccionadas em capa - canal, baseadas na geometria do colmo (Durante et al., 2019).

Por fim, destaca-se que a pesquisa-ação permitiu que a comunidade não só participasse do diagnóstico da situação problema como das ações para mitigá-la. Por esse motivo, os resultados $e$ as soluções propostas foram acessados $e$ incorporados rapidamente, possibilitando a melhoria do processo construtivo em curto prazo.

\section{Agradecimentos}

Conselho Nacional de Desenvolvimento Científico e Tecnológico (CNPq). Processo n. 402387/2016-3.

\section{Referências}

Alves J. Habitação popular em madeira: avaliação pósocupação na cidade de Rio Branco. Revista Amazônia Moderna, 1(2): 72-85, 2018.

Amaro EKP. 2017. Vivências de bioconstrução: um caminho para a leitura da paisagem. Dissertação (Mestrado em Arquitetura e Urbanismo) - Universidade Estadual Paulista "Júlio de Mesquita Filho", Bauru, 335f.

Asquith L \& Vellinga M. 2005. Vernacular Architecture in the Twenty-first century. London and New York: Taylor \& Francis Group, CRC Press, 437p.

Baldissera A. Pesquisa-ação: uma metodologia do "conhecer" e do "agir" coletivo. Sociedade e Debate, 7(2): 5-25, 2001.

Barbosa JC, Morales EAM, Souza AJD de, Campos CI de \& Araújo VA de. 2011. Estudo de tipologias construtivas vernaculares em madeira pós-enchente em São Luiz do Paraitinga, Brasil, p. 1-7. In: CIMAD 11 $-1^{\circ}$ Congresso Ibero-LatinoAmericano da Madeira na Construção. Anais do CIMAD 11, Coimbra, Portugal.

Brito LS de. Construção alternativa para unidades habitacionais de baixa renda em técnica de taipa. Revista Somma, 5(1): 110-126, 2019.

Camillis PK de. 2016. Organizando com barro: a bioconstrução como prática de cooperação. Tese (Doutorado em Administração) - Universidade Federal do Rio Grande do Sul, Porto Alegre, $251 f$.

Catarino C. Bioconstrução combina técnicas milenares com inovações tecnológicas. Inovação Uniemp, 2(5): 46-47, 2006.
Coimbra JM. O mutirão no processo construtivo de casas de barro: vantagens e limitações. Mix Sustentável, 3(4): 47-61, 2017.

Costa SK. Sustentabilidade do processo construtivo habitacional vernacular na aldeia Indígena Itapoã Tupinambá de Olivença/BA/Brasil. Revista Iberoamericana de Ciências Ambientais, 10(1): 65-76, 2019. DOI: 10.6008/CBPC2179-6858.2019.001.0006

Damasceno M. 2018. Pesquisa-ação e possibilidades de interculturalidade crítica e descolonialidade acadêmica junto à comunidade Kanhgág Por Fi em São Leopoldo/ RS. Dissertação (Mestrado em Ciências Sociais) Universidade do Vale do Rio dos Sinos - UNISINOS, São Leopoldo, $118 f$.

Donovan K \& Gkartzios M. Architecture and rural planning: Claiming the Vernacular. Land Use Policy, 41: 334-343, 2014. DOI: http://dx.doi.org/10.1016/j. landusepol.2014.06.013.

Durante LC, Alencar SG, Venere PC, Callejas IJA, Rabelo O da S \& Rossetti K de AC. Coberturas ecológicas para aplicação em moradias dos assentamentos da reforma agrária: alternativas de ecoinovação. Engineering and Science, 8(1): 41-61, 2019. DOI: http://dx.doi.org/10.18607/ES201988148

Garrido E, Brandão MG \& Castro O. Uma nova gestão ambiental para a construção civil na busca da sustentabilidade. Revista Gestão e Gerenciamento, 1(3): 1-8, 2016.

Hărmănescu $\mathrm{M}$ \& Enache $\mathrm{C}$. Vernacular and Technology: InBetween. Procedia Environmental Sciences, 32: 412-419, 2016.

Macedo C. 2010. Construção em terra: uma opção sustentável para a realidade urbana dos países em desenvolvimento - o caso de África, p. 253-261. In: TERRA BRASIL, III Congresso de Arquitetura e Construção com Terra no Brasil. Anais do TERRA BRASIL, Campo Grande, MS.

Moroni Filho E. 2017. Patologias da arquitetura em terra em município do período colonial em Minas Gerais, Brasil, p. 1-11. SIAUS - $1^{\circ}$ Simpósio Internacional de Artes Urbanidades e Sustentabilidade. Anais do $1^{\circ}$ SIAUS, São João Del Rei.

Monteiro LC \& Pires C de A. Bioconstrução e agroecologia: um relato de uma construção alternativa. Cadernos de Agroecologia, 13(1):1-6, 2017.

Monte LO. 2014. Materiales low tech: propuesta de soluciones constructivas para una vivienda unifamiliar em dénia. Trabalho Final de Graduação - ETS de Ingeniería de Edificación Universitat Politècnica de València, Espanha, 232f.

Neideck GK, Granato LM \& Funfgelt K. Bioconstrução de taipa de mão: uma antiga técnica para uma nova maneira de armazenamento de grãos e sementes. Scientia Prima, 6(1): 17-33, 2020. 
Neves C, Farias OB. 2011. Tecnologias de construção com terra. Bauru: FEB-UNESP/ PROTERRA., 80p.

Obata SH \& Ghattas MH. 2012. Bioconstrução: a forma básica para a sustentabilidade das construções, p. 148152. In: XII Safety, Health and Environment World Congress. Anais do XII Safety, Health and Environment World Congress, São Paulo.

Olender MCHL. 2006. A técnica do pau-a-pique: subsídios para a sua preservação. Dissertação (Mestrado em Arquitetura e Urbanismo) - Universidade Federal da Bahia, Salvador, $146 f$.

Oliver P. 2006. Built to meet needs: cultural issues in Vernacular Architecture. Oxford: Elsevier LTDA, 380p.

Pinha PRS, Prompt CH, La Noce EM \& Amoras A da S. Bioconstrução na Reserva Biológica do Lago Piratuba: Sustentabilidade e Tecnologias Apropriadas. Biodiversidade Brasileira, 5(1): 74-93, 2015.

Pinheiro FA. 2010. Bioconstruções em Comunidades Tradicionais, p. 445-454. In: TERRA BRASIL, III Congresso de Arquitetura e Construção com Terra no Brasil. Anais do TERRA BRASIL, Campo Grande, MS.

Pisani MAJ. Taipas: A Arquitetura de Terra. Sinergia, 5(1): 09-15, 2004.

Ribeiro GL, Cabral BF, Ferreira GL, Pinto EL, Sales $\mathrm{AB}$ \& Bonando D. Mutirão de Bioconstrução no Yebá: construindo diálogos e compartilhando saberes. Cadernos de Agroecologia, 13(1): 1-7, 2018.

Santos VR dos \& Costa SK. Do Solo à Bioconstrução: uma ação de Educação Ambiental na aldeia indígena Itapoã Tupinambá de Olivença, Ilhéus/BA. Revista Educação Ambiental em Ação, 72: 1-15, 2020.

Santos MF dos A, Santos M dos A \& Marques HR. $\mathrm{O}$ pensamento sistêmico de Bert Hellinger como instrumento para o desenvolvimento da humanidade. Revista CCCSS Contribuciones a las Ciencias Sociales, 2019. Disponivel: https:/www.eumed.net/rev/ cccss/2019/11/pensamento-bert-hellinger.html
Santos SC dos \& Costa SK. Arquitetura Vernacular ou popular brasileira: conceitos, aspectos construtivos e identidade cultural local. Cadernos de Arquitetura e Urbanismo, 24(35): 218-258, 2018. DOI: https://doi. org/10.5752/P.2316-1752.2017v24n35p218

Santos AAP \& França S. 2009. Caracterização espaço temporal do regime pluviométrico da Região Sul da Bahia, p. 14-33. In: $9^{\circ}$ Seminário de pós-graduação em geografia da UNESP: "teorias e metodologias da geografia: tendências e perspectivas". Anais do $9^{\circ}$ Seminário de pós-graduação em geografia da UNESP, Rio Claro, SP.

Santos HG dos, Jacomine PKT, Anjos LHC dos, Oliveira VA de, Lumbreras JF, Coelho MR, Almeida JA de, Araújo Filho JC de, Oliveira JB de \& Cunha TJF. Sistema Brasileiro de classificação dos solos. Brasília: EMBRAPA SOLOS, 2006.

Sharma V, Marwaha BM \& Vinayak HK. Enhancing durability of adobe by natural reinforcement for propagating sustainable mud housing. International Journal of Sustainable Built Environment, 5(1): 141-155, 2016. DOI: https://doi.org/10.1016/j.ijsbe.2016.03.004

Siolari M, Cardoso F de P \& Hironaga LS. 2010. Arquitetura, participação popular e o "vício da virtude" da construção com terra em assentamentos de reforma agrária, p. 436-444. In: TERRA BRASIL, III Congresso de Arquitetura e Construção com Terra no Brasil. Anais do TERRA BRASIL, Campo Grande, MS.

Tripp D. Pesquisa-ação: uma introdução metodológica. Educação e Pesquisa, 31(3): 443-466, 2005.

Thiollent M. 1985. Metodologia da Pesquisa-ação. São Paulo: Editora Cortez, 109p.

$$
\begin{gathered}
\text { Biodiversidade Brasileira - BioBrasil. } \\
\text { Fluxo Contínuo } \\
\text { n. 3, } 2021
\end{gathered}
$$

http://www.icmbio.gov.br/revistaeletronica/index.php/BioBR

Biodiversidade Brasileira é uma publicação eletrônica científica do Instituto Chico Mendes de

Conservação da Biodiversidade (ICMBio) que tem como objetivo fomentar a discussão e a disseminação de experiências em conservação e manejo, com foco em unidades de conservação e espécies ameaçadas.

ISSN: 2236-2886 